doi: $10.15407 /$ ujpe62.03.0240

O.V. KHOROLSKYI, O.P. RUDENKO, O.M. ZAYMACK

V.G. Korolenko National Pedagogical University of Poltava

(2, Ostrogradskyi Str., Poltava 36000, Ukraine; e-mail: khorolskiy.alexey@gmail.com)

\title{
PECULIARITIES OF CHANGES IN TIME OF ELECTRICAL PROPERTIES OF POLYVINYL PACS 61.25.H-, 64.90.+b ALCOHOL IN DIMETHYL SULFOXIDE SOLUTIONS
}

\begin{abstract}
Long-term changes of the dielectric constant of concentrated (5, 10, and 15 wt.\%) solutions of low-molecular polyvinyl alcohol in dimethyl sulfoxide have been studied in a frequency interval of 0.5-200 kHz and at a temperature of $290 \pm 1 \mathrm{~K}$. A hypothesis is put forward that the time evolution of dielectric constant is governed by changes in the supramolecular structure of the polymer solution; those changes have a fluctuation nature and are associated with the establishing of equilibrium in the polymer solution. Using the law of corresponding states, a similarity between the kinetics of equilibrium establishment in the polyvinyl alcohol-dimethyl sulfoxide and glycerol-water solutions is demonstrated. With the help of a proposed mathematical model, the characteristic lifetimes and oscillation frequencies of microscopic inhomogeneities in the polyvinyl alcohol solution are determined.

Keywords: dielectric permittivity, polyvinyl alcohol solutions, dimethyl sulfoxide, thermodynamic equilibrium.
\end{abstract}

\section{Introduction}

Liquid solutions of polyvinyl alcohol (PVA) are used in the textile and paper industries, cosmetics, agriculture, pharmacology, and medicine $[1,2]$. In the chemical technology, water, as a rule, is a main solvent for PVA [1]. However aqueous PVA solutions tend to form gels: an irreversible growth of the viscosity of the concentrated aqueous PVA solutions in time is observed [3,4]. Aqueous PVA solutions are widely applied in medicine as cryogels and polymeric matrices for dosage forms [5,6], for the film coating of tablets, and as nutrient media [7]. They are used in ophthalmology and are a component of membranes for dialysis [8-10]. From the thermodynamic viewpoint $[11,12]$, dimethyl sulfoxide - $\left(\mathrm{CH}_{3}\right)_{2} \mathrm{SO}, \mathrm{DMSO}$ - is a better solvent for PVA than water. DMSO is an aprotic organic solvent. Owing to its nontoxical influence on the human body, it founds applications in various branches of medicine: dermatology, ophthalmology, neurology, psychiatry, gastroenterology, rheumatology, oncology, and surgery [13-16]. Therefore, the research of the physical properties of polyvinyl alcohol solutions in dimethyl sulfoxide is a challenging

(c) O.V. KHOROLSKYI, O.P. RUDENKO, O.M. ZAYMACK, 2017 task for the physics of liquid systems, as well as for experimental medicine and pharmacology.

The aim of this work is (i) to study the character of equilibrium establishment in the solution of PVA in DMSO and (ii) to determine the characteristic time of equilibrium establishment in this solution and its dependence on the solution concentration. In order to find those regularities, the time evolution of the dielectric permittivity of PVA solutions in DMSO is studied as a function of the frequency and concentration.

\section{Experimental Part}

\subsection{Research object and the procedure of dielectric permittivity measurement in solutions}

Polyvinyl alcohol is a flexible-chain polymer of the aliphatic series. In its macromolecular chain, it contains hydroxyl groups that are responsible for the formation of intra- and intermolecular hydrogen bonds. For the experiments, polyvinyl alcohol Mowiol 4-98 (Kuraray) with a hydrolysis degree of $98.4 \pm 0.4 \mathrm{~mol} . \%$ and without additional purification was used. Earlier, with the help of the viscosimetric method, we determined that the average polymerization degree in this alcohol amounts to $\bar{p}=600$,

ISSN 2071-0194. Ukr. J. Phys. 2017. Vol. 62, No. 3 
which corresponds to a low-molecular polyvinyl alcohol [11]. As a solvent, DMSO of the pharma grade was used, which was held on $\mathrm{NaOH}$ and distilled at a low pressure of 3-5 $\mathrm{mm} \mathrm{Hg}$. The middle fraction was collected, by following the method of work [17].

The solutions were prepared gravimetrically. The main method to speed up the polymer dissolution was the intense stirring, which considerably shifted the gradients of a hydrodynamic field and, thus, promoted a detachment of the surface highly viscous layer of the solution [19]. A sealed flask with the solvent and PVA was placed on a water bath with a temperature of $90-95{ }^{\circ} \mathrm{C}$, and the mixture was dissolved under the permanent stirring during 6-12 h until a visually homogeneous solution was obtained. The prepared solutions were stored in hermetically sealed containers in a dark dry place with annual temperature oscillations within an interval from 288 to $298 \mathrm{~K}$

The dielectric permittivity of PVA solutions in DMSO with concentrations of 5, 10, and 15 wt. $\%$ at a fixed temperature of $290 \pm 1 \mathrm{~K}$ was experimentally studied, by using the bridge measurement method in a frequency interval of $0.5-200 \mathrm{kHz}$. The method applied was described in work [18] in detail. The total relative error of measurements did not exceed $2 \%$.

An installation for studying the electrical properties of liquid systems was created and described by the authors of work [18]. It corresponds to the functional of the ac bridge R5083 and was tested on classical liquids. The bridge circuit includes a quadripole, whose transmission coefficient equals zero under certain conditions, which are called "bridge balance conditions". The bridge is intended to determine the electrical parameters of liquids in a frequency interval of $0.5-200 \mathrm{kHz}$. It consists of an electronic bridge fabricated with the use of operational amplifiers, a voltage summator, a power unit for operational amplifiers, a measuring plane condenser (its disks are covered with fluoroplastic films in order to increase the active resistance of liquids), a generator of sound pulses G3-118 (0.5-200 kHz), and a millivoltmeter V3-38 serving as an indicator of the electronic bridge balance. The dielectric permittivity $\varepsilon$ is determined as the ratio between the capacitance of a condenser filled with a medium and the capacitance of the same condenser, but in air. A simplified circuit diagram of the electronic bridge is exhibited in Fig. 1.

\subsection{Preparation of polyvinyl alcohol solutions in dimethyl sulfoxide}

Owing to a large size of macromolecules and a considerable interaction between molecules, the process of polymer dissolution - in particular, polyvinyl alcohol - has a number of specific features in comparison with the dissolution of low-molecular substances. The first dissolution stage for an arbitrary polymer is its swelling: this is a sorption process of a low-molecular liquid by the polymer, which is accompanied by an increase of the polymer volume and mass and by a conformational change of macromolecules. At the swelling, mobile solvent molecules penetrate into the space between polymer molecules (first, as a rule, in amorphous regions) and draw their chains apart by breaking the intermolecular bonds [20]. Large polymer molecules have low diffusion coefficients. Therefore, the mixing runs slowly and requires a substantial time interval. The diffusion of the solvent into the polymer results in a gradual break of the intermolecular contacts between chains and increases their mobility. The process runs faster, if the macromolecules are more flexible, and the density of their packing is lower.

As the polymer concentration grows, the structure of polymer solution changes. It transforms from isolated macromolecules in diluted solutions (there, they form coagulated coil-like conformations [21]) to aggregates and, after achieving a critical concentration for the macromolecular coils to overlap (the so-called crossover concentration $C^{*}$ ), a network of intermolec-

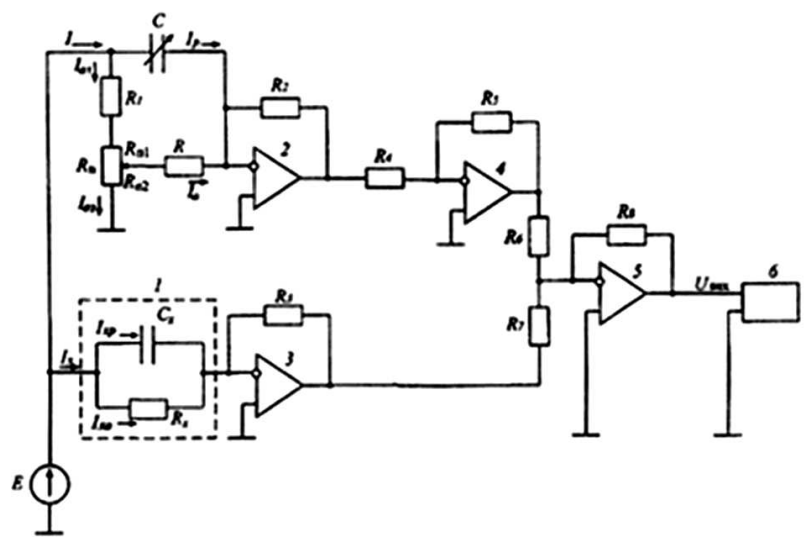

Fig. 1. Circuit diagram of the electronic bridge: the equivalent circuit of a measuring condenser (1), integrated operational amplifiers (2-5), millivoltmeter $(6)$, variable condenser $(\mathrm{C})$, calibrated potentiometer $\left(\mathrm{R}_{\mathrm{P}}\right)$, sound generator $(\mathrm{E})$ 


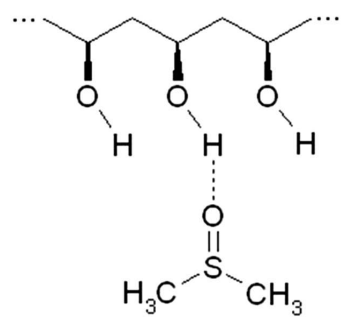

Fig. 2. Diagram of hydrogen bond formation between a monomer of a PVA macromolecule and a DMSO molecule

ular links is formed. Earlier, we demonstrated in work [11] that the critical crossover concentration equals 2.93 wt.\% for the aqueous solutions of PVA Mowiol 4-98 with a hydrolysis degree of $98.4 \pm 0.4 \mathrm{~mol} . \%$. If the PVA concentration grows further, there emerge spatial molecular networks in the solution, because the average distance between the macromolecules becomes shorter, and the segmentary motion of macromolecular chains more complicated, i.e. semidiluted solutions become concentrated. In the concentrated aqueous PVA solutions, the irreversible process of gel formation takes place $[3,4]$. It manifests itself as an increase of the solution shift viscosity in time until hydrogel is formed. According to the results of works [22, 23], the process of gel formation in aqueous PVA solutions is similar to the crystallization due to small sizes of hydroxyl groups in the macromolecule. For concentrated PVA solutions in DMSO, at least up to a concentration of $15 \mathrm{wt} . \%$, we did not observe the process of gel formation visually, although the crossover concentration for the examined PVA solutions in DMSO was determined to equal 1.74 wt.\% [11]. The macromolecules slowly diffuse into the solvent, and the tendency to the transformation into a homogeneous single-phase solution is observed. But the entropy of this single-phase system is relatively low. Therefore, the system will try to become a layered structure. There appear compact regions (interlayers, droplets) of the solution with different concentrations of the dissolved component. We face the same situation in the aqueous solutions of low-molecular alcohols, in particular, of the methanol series [24]. Owing to fluctuations, a permanent transition to a homogeneous solution and its further stratification take place.

\section{Theoretical Part}

From the energy viewpoint, a polymer can be dissolved, if the total energy of interaction between the polymer and solvent molecules exceeds the energies of interaction of the solvent molecules with one another and of the polymer molecules with one another. The dissolution process of the polymer as a low-molecular compound is accompanied by a reduction of the free energy.

From the structure of the PVA formula, it follows that hydrogen bonds can be formed between the elementary links of either the same molecule or two different molecules. Those links play a key role in that a linear macromolecule becomes coiled into a globule in diluted solutions owing to the formation of intersegment hydrogen bonds. If DMSO is added, hydrogen bonds are also formed between the elementary links of PVA and DMSO molecules (Fig. 2). In works $[25,26]$, it was shown that hydrogen bonds are not equivalent: the energy of hydrogen bonds equals $E_{\mathrm{HB}}=-36.3 \mathrm{~kJ} / \mathrm{mol}$ for the interaction of the PVAPVA type and to $E_{\mathrm{HB}}=-29.4 \mathrm{~kJ} / \mathrm{mol}$ for the interaction of the PVA-water type. As a result, there appears the tendency for PVA to dissolve.

According to the ideas formulated above, the establishment of equilibrium in a solution is accompanied by the emergence of a microscopic inhomogeneous structure in it. This structure is realized in the form of compact regions (layers or droplets) with various PVA concentrations and corresponds to the maximum entropy. Owing to fluctuations, some layers permanently transform into others and vice versa (the same is also valid for the variations of droplet sizes). Actually, this means that the character of relaxation does not depend on the specific molecular structures of the solvent and the solute. So we hope for that the character of relaxation in the PVADMSO solution is similar in many respects to that in the aqueous solutions of alcohols belonging to the methanol series and glycerol. In other words, the time dependence of the sizes of compact regions can be described by the dependence

$r(t)=r_{0} \sin \left(\omega_{f} t\right) \exp \left(-\frac{t}{\tau}\right)$

where $r_{0}$ and $\tau$ are the initial size and the characteristic lifetime, respectively, of microscopic inhomogeneity; and $\omega_{f}$ is a frequency corresponding to the size oscillations of microscopic inhomogeneities as a result of the surface molecular diffusion from the layer and into it.

ISSN 2071-0194. Ukr. J. Phys. 2017. Vol. 62, No. 3 
Note that the characteristic lifetime of microscopic inhomogeneities, $\tau$, is also governed by the surface diffusion. We may assume that the same law should describe the time evolution of the dielectric permittivity of PVA solutions in DMSO, as well as the polarized molecular scattering of light. Furthermore, it is quite expected that the lifetimes of microscopic inhomogeneities and the oscillations of their shape in the PVA-DMSO and glycerol-water systems should satisfy the relation

$$
\frac{\tau(\mathrm{PVA}-\mathrm{DMSO})}{\tau(\text { glycerol-water })} \approx \frac{\omega_{f}(\text { glycerol-water })}{\omega_{f}(\mathrm{PVA}-\mathrm{DMSO})} .
$$

\section{Experimental Results and Their Discussion}

In order to reveal the process of gel formation in the PVA solutions in DMSO, the research of the dielectric permittivity of the concentrated PVA solutions in DMSO within long time intervals (up to 3 years) and at the same experimental temperature was carried out. Dielectric spectroscopy as a structure-sensitive method to study liquid systems allows changes in the molecular structure of solutions to be analyzed.

Unidirectional processes of variation in the dielectric permittivity with time in the concentrated PVA solutions in DMSO would have been quite expected. The growth of the dielectric permittivity of concentrated polymer solution in time would correspond to the dispersion of macromolecules in the solvent, when the macromolecules were surrounded by bound DMSO molecules. On the contrary, a decrease of the dielectric permittivity of the concentrated polymer solution in time would testify to a growth of the number of intermolecular links, which would correspond to the process of gel formation or other temporal variations in the polymer solution ("aging", photochemical processes, and so on). Instead, wave-like temporal changes of the dielectric properties of polyvinyl alcohol solutions in dimethyl sulfoxide were observed. In Figs. 3 to 8, the time dependences of the dielectric permittivity of PVA solutions in DMSO with concentrations of 5, 10, and 15 wt. $\%$ at frequencies from 0.5 to $200 \mathrm{kHz}$ are depicted. Not numerous experimental points were approximated by dashed curves plotted with the use of formula (3).

Figures 3 to 8 demonstrate oscillations of the dielectric permittivity of concentrated PVA solutions

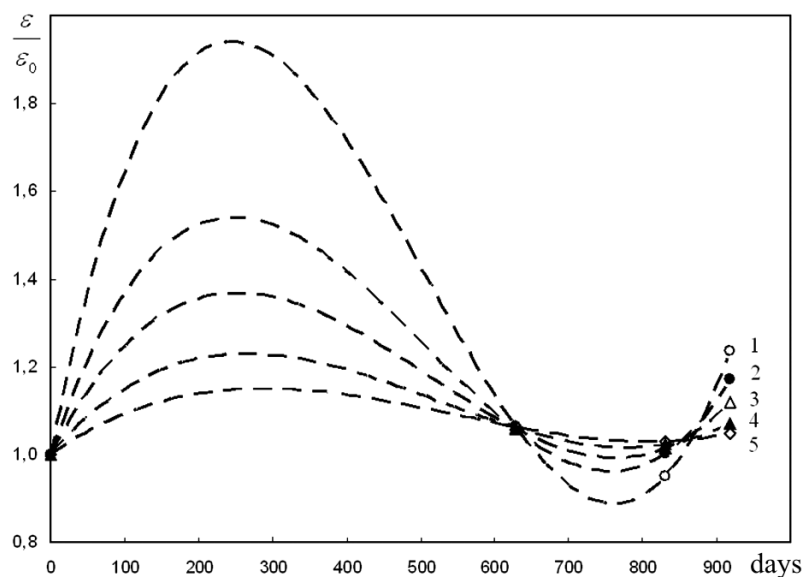

Fig. 3. Dependences of the relative dielectric permittivity on the preparation time for the PVA solution in DMSO with a concentration of $5 \mathrm{wt} \%$ at various frequencies: 2 (1), 4 (2), 6 (3), 10 (4), and $200 \mathrm{kHz}$ (5). Dashed curves demonstrate approximations by formula (3)

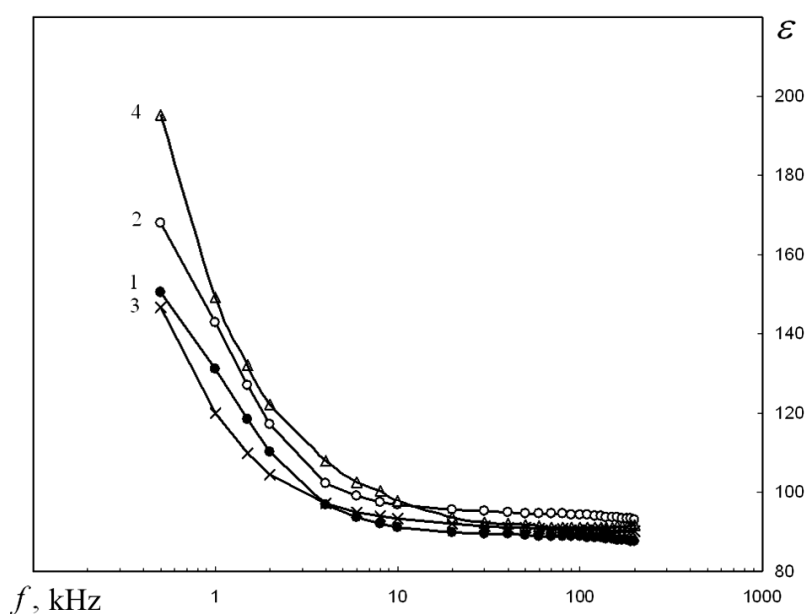

Fig. 4. Frequency dependences of the dielectric permittivity of the PVA solution in DMSO with a concentration of 5 wt.\% measured in 0 (1), 628 (2), 831 (3), and 918 days (4) after the preparation of the solution

in DMSO in time. The higher the electric field frequency, the smaller is the corresponding variation amplitude. For instance, if the frequency equals $200 \mathrm{kHz}$, the dielectric permittivity oscillates within the limits of $7 \%$. The largest oscillations of the dielectric permittivity are observed at low frequencies from 0.5 to $2 \mathrm{kHz}$. In particular, at a frequency of $500 \mathrm{~Hz}$, the variation reaches $30 \%$ of the initial value. This fact can testify to temporal modifications in the molecular structure of the polymer solution; namely, the 


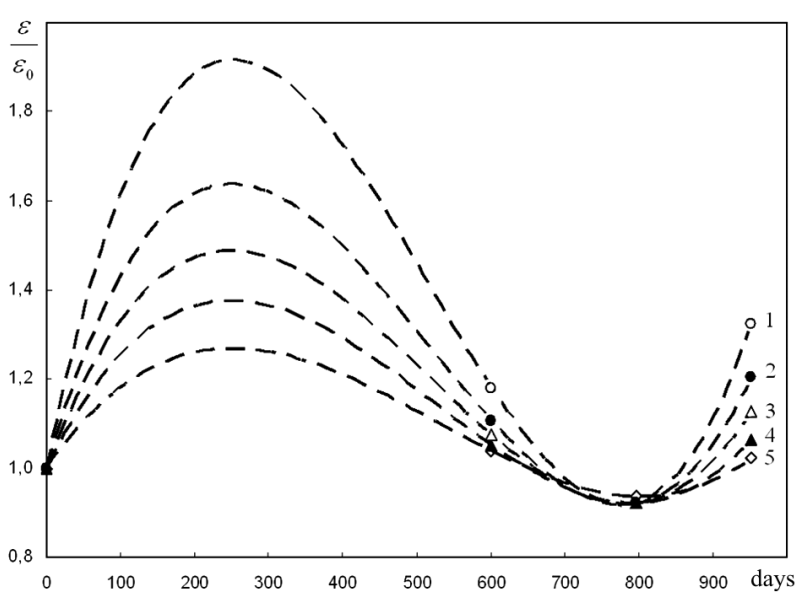

Fig. 5. The same as in Fig. 3, but for the PVA solution in DMSO with a concentration of $10 \mathrm{wt} . \%$

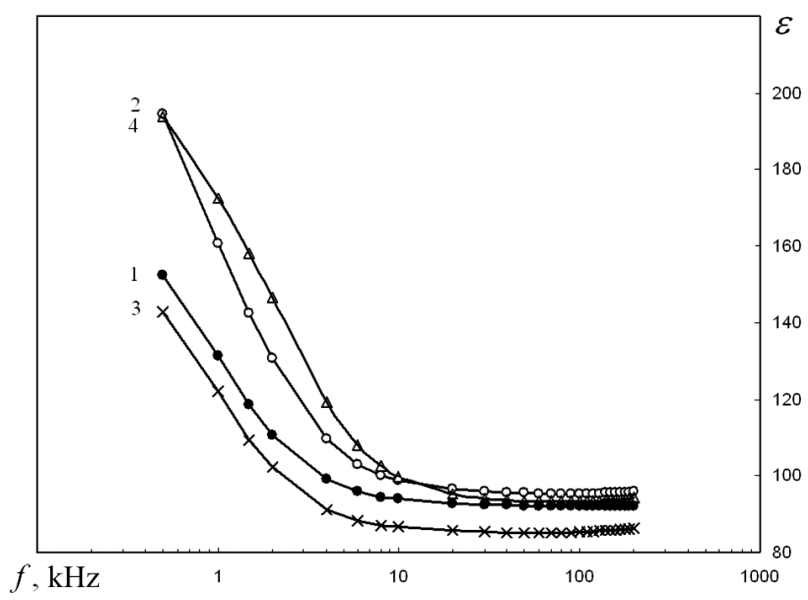

Fig. 6. Frequency dependences of the dielectric permittivity of the PVA solution in DMSO with a concentration of $10 \mathrm{wt} . \%$ measured in 0 (1), 601 (2), 796 (3), and 952 days (4) after the preparation of the solution

oscillations can correspond to the low-frequency processes of intermolecular link reconstruction, which are associated with the motion of some segments in the macromolecular chain. The changes can testify to the process of thermodynamic equilibrium establishment in the concentrated polymer solutions. This conclusion would have not invoked considerable discussions, if the experimental time intervals had not been so long (the experiment with the 10-wt.\% PVA solution in DMSO lasted for 952 days or $8.22 \times 10^{7} \mathrm{~s}$ ). Can we suppose that there are the long-term processes of equilibrium establishment in the concentrated polymer solutions?

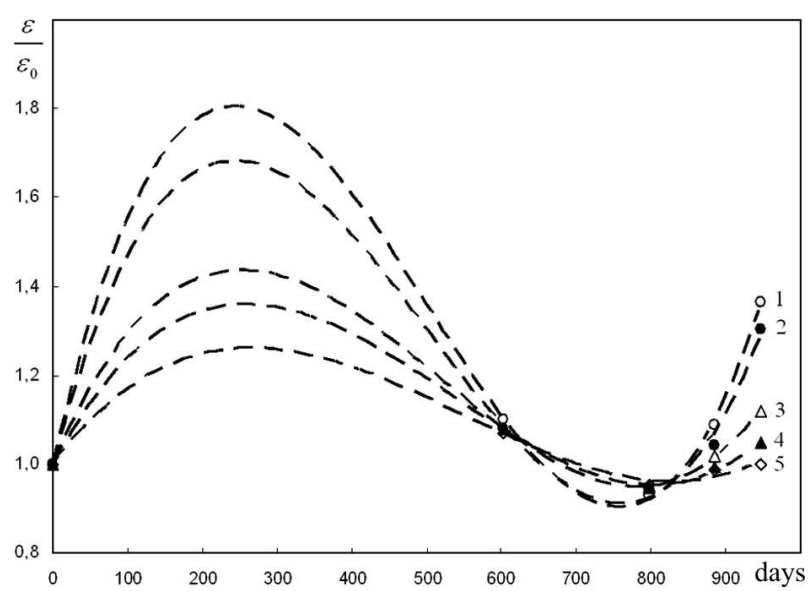

Fig. 7. The same as in Fig. 3, but for the PVA solution in DMSO with a concentration of 15 wt. $\%$

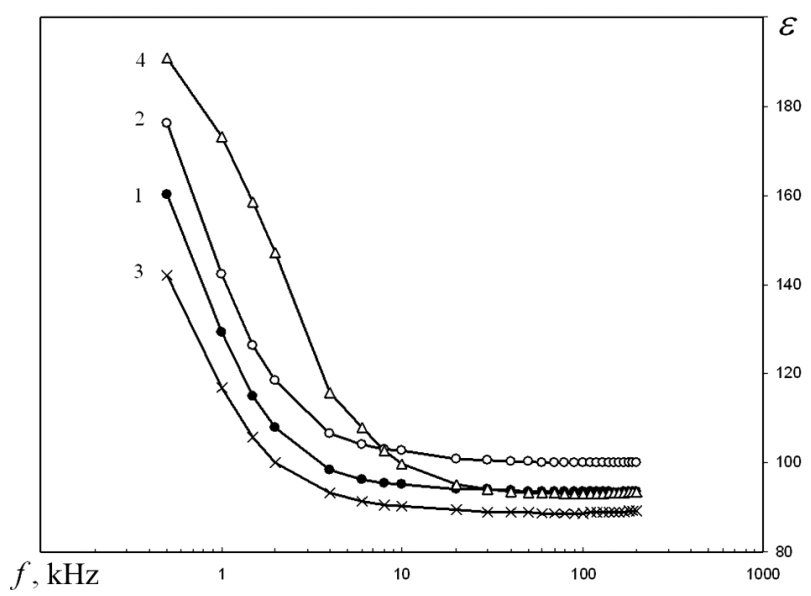

Fig. 8. Frequency dependences of the dielectric permittivity of the PVA solution in DMSO with a concentration of $15 \mathrm{wt} \%$ measured 0 (1), 603 (2), 798 (3), and 947 days (4) after the preparation of the solution

In a number of works [27-29], the issue concerning the time intervals for the establishment of an equilibrium state in aqueous solutions of monoatomic alcohols was discussed. We would like to point out the results of works $[24,30,31]$, in which the methods of integral intensity of molecular light scattering and dynamic light scattering (laser correlation spectroscopy) were used to show that, for an equilibrium state in aqueous alcohol solutions to be established, a time interval is required that can reach one or two weeks after the preparation of the solution. It is worth paying attention that the examined systems have an intermolecular network of hydrogen bonds, and the sizes of

ISSN 2071-0194. Ukr. J. Phys. 2017. Vol. 62, No. 3 
the solvent (water) and solute (aliphatic monoatomic alcohols, glycerol) molecules in them are close (comparable). On the other hand, for vitreous substances, which are amorphous systems in a metastable state, the time required to reach the thermodynamic equilibrium can be adopted, with certain reservations, as tending to infinity $[32,33]$.

An approximation for the damped oscillations of the dielectric permittivity of concentrated PVA solutions in DMSO was sought in the form similar to formula (1):

$\varepsilon(t)=\varepsilon_{0} \sin \left(\omega_{f} t\right) \exp \left(-\frac{t}{\tau}\right)+\varepsilon_{m}$,

where $\omega_{f}$ and $\tau$ have the same meaning as in formula (1). The results of the approximation for the researched PVA solutions in DMSO at a frequency of $1 \mathrm{kHz}$ are depicted in Fig. 10 and quoted in Table.

If, according to Fig. 9 taken from work [30], the characteristic lifetime of a microscopic inhomogeneity in the glycerol-water system is put equal to one day, and the oscillation period to approximately $4 \mathrm{~h}$ (0.167 day), then relation (2) and Table yield

$$
\begin{aligned}
& \frac{\tau(\text { PVA-DMSO })}{\tau(\text { glycerol-water })} \approx \frac{\omega_{f}(\text { glycerol-water })}{\omega_{f}(\text { PVA-DMSO })} \Rightarrow \\
& \Rightarrow \frac{966.7}{1.0} \approx \frac{1 \div 0.167}{1 \div 164.3} \Rightarrow 966.7 \approx 983.8,
\end{aligned}
$$

So, one can see that the kinetics of the equilibrium establishment processes in the PVA-DMSO solutions is similar to that in the aqueous glycerol solutions.

The presented arguments give us a ground to assert that there exist long-term processes of thermodynamic equilibrium establishment in the concentrated solutions of polyvinyl alcohol in dimethyl sulfoxide. The obtained values of the time intervals

Characteristic lifetimes of microscopic inhomogeneities, $\tau$, and oscillation frequencies, $\omega_{f}$, for various PVA concentrations in DMSO at a frequency of $1 \mathrm{kHz}$ calculated by formula (3)

\begin{tabular}{|c|c|c|}
\hline $\begin{array}{c}\text { PVA concentration, } \\
\text { wt.\% }\end{array}$ & $\begin{array}{l}\omega_{f}^{-1}, \\
\text { days }\end{array}$ & $\begin{array}{c}\tau, \\
\text { days }\end{array}$ \\
\hline 5 & 168.2 & 966.7 \\
10 & 165.3 & 966.7 \\
15 & 159.5 & 966.7 \\
\hline
\end{tabular}

ISSN 2071-0194. Ukr. J. Phys. 2017. Vol. 62, No. 3
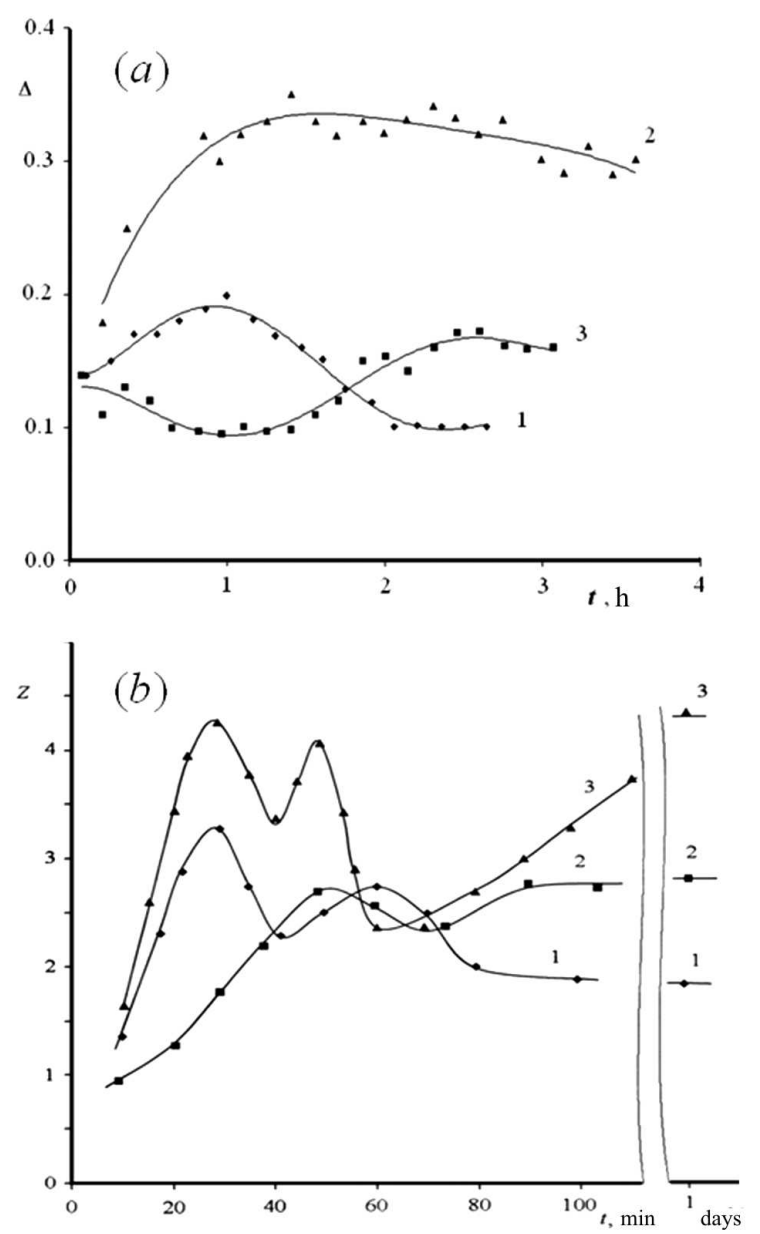

Fig. 9. Dependences of the coefficient of scattered light depolarization in water-glycerol solutions on the time interval spent after the preparation of the solution. The mole fraction of glycerol in the solution $x=0.031$ (1), 0.035 (2), and 0.046 (3). The temperature is $10{ }^{\circ} \mathrm{C}$. Curve 3 corresponds to the concentration, at which the abnormal peak in the light scattering is observed (a). Angular asymmetry of the scattered light intensity as a function of time after the preparation of the aqueous glycerol solution by the ultrasonic mixing $(b)$. The mole fraction of glycerol in the solution $x=0.047(1), 0.035$ (2), and 0.056 (3). The figures were taken with permission from work [30]

required for the thermodynamic equilibrium in the PVA-DMSO solutions to be established seem to be reliabl if we take into consideration that the sizes of solute (PVA) macromolecules (in various spatial conformations) can differ by several orders of magnitude from the size of solvent (DMSO) molecule. Our arguments are confirmed by the results of works [34-36], 

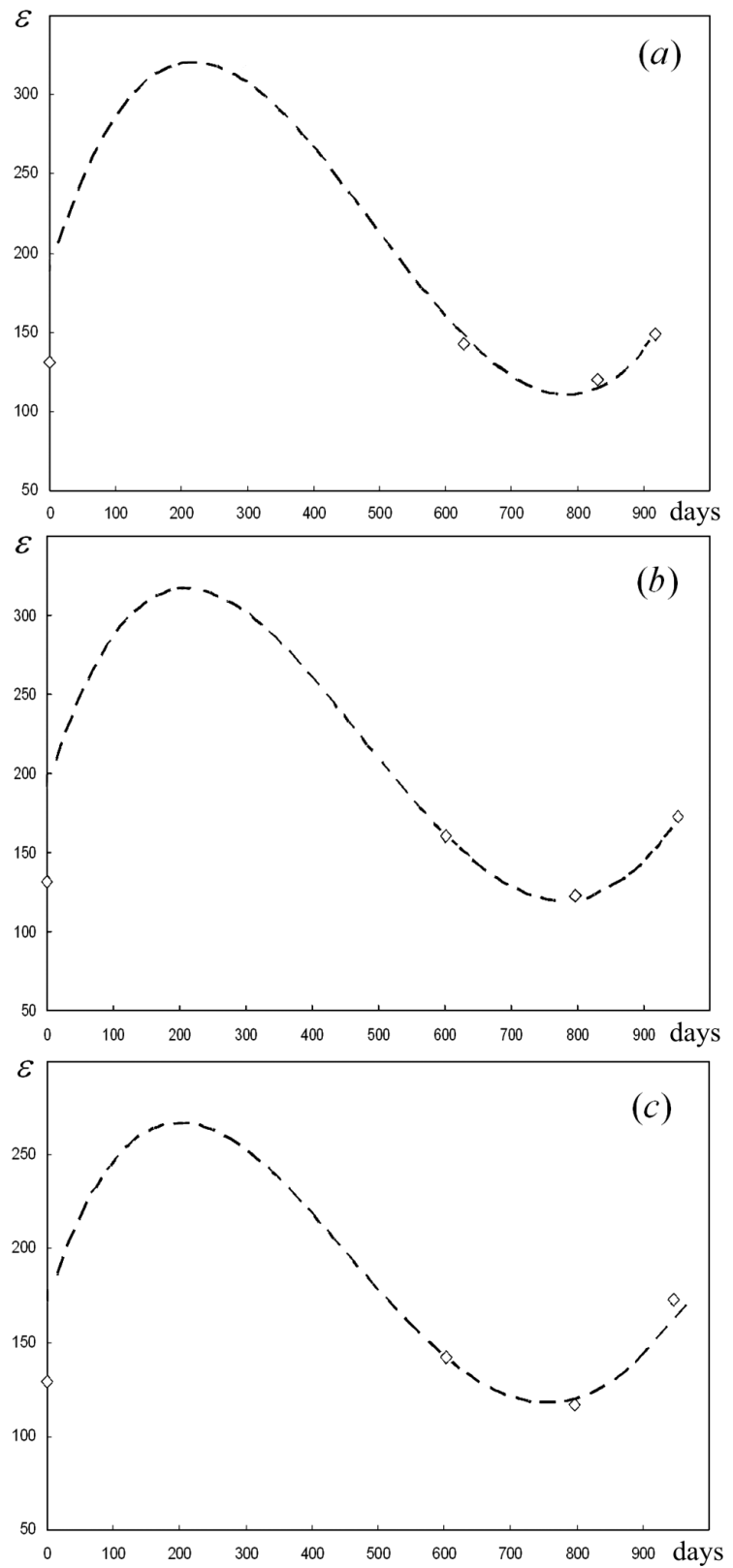

Fig. 10. Experimental data for the dielectric permittivity of PVA solutions in DMSO with concentrations $5(a), 10(b)$, and 15 wt.\% (c) at a frequency of $1 \mathrm{kHz}$ (diamonds) and their approximations by formula (3) (dashed curves)

in which it was noted that, owing to a high viscosity of polymer solutions, the equilibrium in them is established more slowly in the solutions with higher polymer concentrations and can last for several months. A confirmation or refutation of this statement demands for further researches, which will be reported in our future works.

\section{Conclusions}

1. Long-term oscillations of the dielectric permittivity within the frequency interval of $0.5-200 \mathrm{kHz}$ were revealed in concentrated solutions of low-molecular polyvinyl alcohol in dimethyl sulfoxide with concentrations of 5,10 , and $15 \mathrm{wt} . \%$ at a constant temperature of $290 \pm 1 \mathrm{~K}$, which testifies to periodic structural variations in those polymeric solutions.

2. The assumption was put forward that the oscillations of the dielectric permittivity of concentrated polyvinyl alcohol solutions in dimethyl sulfoxide have a fluctuation origin and reflect the establishment of an equilibrium state in the solutions.

3. The law of corresponding states was applied to the PVA-DMSO and glycerol--water systems, which demonstrated similar kinetics of equilibrium establishment in those systems. A mathematical model of damped harmonic oscillations was proposed, which made it possible to determine the characteristic lifetimes and the characteristic oscillation frequencies of microscopic inhomogeneities in the concentrated solutions of polyvinyl alcohol in dimethyl sulfoxide.

The authors express their sincere gratitude to Prof. M.P. Malomuzh and Prof. V.Ya. Gotsulskyi for their methodical help and detailed discussion of experimental results, which stimulated this work. We also grateful to Academician L.A. Bulavin for his permanent attention to our researches and comprehensive support of the work.

1. S N. Ushakov, Polyvinyl Alcohol and Its Derivatives (Izd. Akad. Nauk SSSR, 1960) (in Russian).

2. R.O. Ebewele. Polymer Science and Technology (CRC Press, 2000) [ISBN: 0-0849-8939-9].

3. V.V. Klepko, Yu.B. Mel'nichenko. Kinetics and equilibrium swelling of gelatine gels. Polymer 36, 5057 (1995) [DOI: 10.1016/0032-3861(96)81636-3].

4. Yu.B. Mel'nichenko, L.A. Bulavin. Self-diffusion of water in gelatin gels: 2. Quasi-elastic neutron scattering data. Polymer 32, 3295 (1991) [DOI: 10.1016/00323861(91)90530-v].

5. A.K. Bajpai, S.K. Shukla, S. Bhanu, S. Kankane. Responsive polymers in controlled drug delivery. Prog. Polym. Sci. 33, 1088 (2008) [DOI: 10.1016/ j.progpolymsci.2008.07.005].

ISSN 2071-0194. Ukr. J. Phys. 2017. Vol. 62, No. 3 
6. T.V. Chirila, Ye Hong, P.D. Dalton, I.J. Constable, M.F. Refojo. The use of hydrophilic polymers as artificial vitreous. Prog. Polym. Sci. 23, 475 (1998) [DOI: 10.1016/ S0079-6700(97)00045-2].

7. E.T. Zhilyakova, N.N. Popov, M.Yu. Novikova, O.O. Novikov, M.A. Khalikova, V.I. Deineka. Study of physicochemical and technological characteristics of polyvinyl alcohol with the aim of creating prolonged dosage forms with a liquid dispersion medium. Nauch. Vedom. Belgorod. Gos. Univ. Ser. Medits. Farmats. 99, 109 (2011) (in Russian).

8. A.A. Ryabtseva, Sheikh M.Kh. Rahman. Some modern antihypertensive drugs for the treatment of ophthalmic hypertension and glaucoma. Klin. Oftalmol. 2, 70 (2001) (in Russian).

9. Siddaramaiah, T.M.P. Kumar, V. Ravi. Studies on biopolymers for ophthalmic drug delivery. J. Macromol. Sci. A 44, 229 (2007) [DOI: 10.1080/10601320601031416].

10. J.H. Braybrook, L.D. Hall. Organic polymer surfaces for use in medicine: Their formation, modification, characterisation and application. Prog. Polym. Sci. 15, 715 (1990) [DOI: 10.1016/0079-6700(90)90009-P].

11. O.V. Khorolskyi, O.P. Rudenko. Viscometric research of concentration regimes for polyvinyl alcohol solutions. Ukr. J. Phys. 60, 880 (2015) [DOI: 10.15407/ ujpe60.09.0880].

12. A. Luzar, D. Chandler. Structure and hydrogen bond dynamics of water-dimethyl sulfoxide mixtures by computer simulations. J. Chem. Phys. 98, 8160 (1993) [DOI: $10.1063 / 1.464521]$.

13. V.N. Levenets, A.I. Treshchinskii, V.I. Neroda. To the use of dimethylsulfoxide in surgery. Klin. Khirurg. 3, 67 (1976) (in Russian).

14. I.Ya. Makshanov, A.A. Polynskii, L.I. Krupskii, I.V. Khilmonchik. Dimexidum in the system of prevention and treatment of purulent-septic diseases. Beloruss. Int. Congress Khirurg. 1, 254 (1996) (in Russian).

15. I.Yu. Kiryanov, A.S. Barybin, V.A. Michalchenko. Application of dimethyl sulfoxide (DMSO) in experimental and clinical radiology. Medits. Radiolog. 8, 73 (1976) (in Russian).

16. B.M. Datskovskii, A.S. Zaks, L.S. Mitryukovskii. Dimethyl sulfoxide (pharmacology, application in dermatology and related specialties). In Problems of Experimental Dermatology (Perm, 1973), p. 3 (in Russian).

17. A. Gordon and G. Ford, The Chemist's Companion: A Handbook of Practical Data, Techniques, and References (Wiley, 1972) [ISBN: 978-0-471-31590-2].

18. O.P. Rudenko, V.K. Kalapturovskyi, V.S. Sperkach, V.V. Shylov. Installation for measuring electrical properties of liquids in a frequency range of $10-100 \mathrm{kHz}$. Zbirn. Nauk. Prats PDPU Ser. Fiz. Mat. Nauky 3, 72 (1998) (in Ukrainian).

19. K.E. Perepelkin, M.D. Perepelkina. Soluble Fibers and Films (Khimiya, 1977) (in Russian).

20. Workshop on High-Molecular Compounds, edited by V.A. Kabanov (Khimiya, 1985) (in Russian).
21. G.V. Kozlov, I.V. Doblin, G.E. Zaikov. The Fractal Physical Chemistry of Polymer Solutions and Melts (Apple Academic Press, 2014) [ISBN 978-1-926895-81-9].

22. L.A. Bulavin, N.L. Sheiko, Y.F. Zabashta, T.Y. Nikolayenko. Effect of impurities on elastic properties of ice near the melting point. Ukr. J. Phys. 55, 1045 (2010).

23. L.A. Bulavin, E.Yu. Aktan, Yu.F. Zabashta. Formation of a mesomorphic phase upon melting of folded crystals containing vacancies. Polymer Sci. B 47, 109 (2005).

24. V.Ya. Gotsulskyi. Dr. Sci. thesis. Micro-Heterogeneous Structure of Aqueous Alcohol Solutions and Fluctuations in the Vicinity of Singular Points (Kyiv, 2016) (in Ukrainian).

25. M.S. Rumyantsev, A.V. Gushchin, S.V. Zelentsov. Influence of the hydrogen bond type on the reactivity of hydroxyl groups in the reaction of polyvinyl alcohol acetalation with butanal. Vysokomol. Soed. 54, 1497 (2012) (in Russian).

26. D.J.S. Anand Karunakaran, T. Ganesh, M.M. Sylvester, P. Hudge, A.C. Kumbharkhane. Dielectric properties and analysis of H-bonded interaction study in complex systems of binary and ternary mixtures of polyvinyl alcohol with water and DMSO. Fluid Phase Equilibria 382, 300 (2014) [DOI: 10.1016/j.fluid.2014.09.018].

27. M.F. Vuks, Light Scattering in Gases, Liquids, and Solutions (Leningrad State Univ., 1977) (in Russian).

28. G.P. Roshchina, A.S. Kaurova. Light-scattering research of fluctuations in non-aqueous electrolyte solutions. Ukr. Fiz. Zh. 9, 512 (1964) (in Russian).

29. V.E. Chechko, V.G. Zaremba. Molecular interaction in solutions with the strong hydrogen bond. Khim. Fiz. 12, 1036 (1993)

30. L.A. Bulavin, V.Ya. Gotsulskiy, V.E. Chechko. Peculiarities in the establishment of equilibrium state in diluted aqueous solutions of glycerol. Ukr. J. Phys. 59, 689 (2014) [DOI: 10.15407/ujpe59.07.0689].

31. L.A. Bulavin, V.Ya. Gotsulskyi, N.P. Malomuzh, V.E. Chechko. Relaxation and equilibrium properties of dilute aqueous alcohol solutions. Izv. Ross. Akad. Nauk. Ser. Khim. 4, 851 (2016) (in Russian).

32. W. Eitel. The Physical Chemistry of the Silicates (Univ. of Chicago Press, 1954) [ISBN: 0-226-19813-8].

33. M.M. Shchults, O.V. Mazurin. Modern Concepts of the Structure of Glasses and Their Properties (Nauka, 1988) (in Russian).

34. A.A. Tager. Physical Chemistry of Polymers (Nauchnyi Mir, 2007) [ISBN: 978-589-176-437-8] (in Russian).

35. C. Wohlfarth. CRC Handbook of Thermodynamic Data of Polymer Solutions at Elevated Pressures (CRC Press, 2005) [ISBN: 9780849332463].

36. V.A. Kargin. Colloid Systems and Polymer Solutions (Nauka, 1978) (in Russian).

Received 09.11.16.

Translated from Ukrainian by O.I. Voitenko 
О.В. Хоролъсъкий, О.П. Руденко, О.М. Займак

ОСОБЛИВОСТІ ЗМІНИ 3 ЧАСОМ

ЕЛЕКТРИЧНИХ ВЛАСТИВОСТЕЙ

РОЗЧИНІВ ПОЛІВІНІЛОВОГО СПИРТУ

У ДИМЕТИЛСУЛЬФОКСИДІ

$\mathrm{P}$ е $з$ ю м е

Робота присвячена дослідженню довготривалих змін у часі діелектричної проникності в частотному інтервалі $(0,5-$ $200)$ кГц при температурі $(290 \pm 1) \mathrm{K}$ концентрованих розчинів низькомолекулярного полівінілового спирту в диметил- сульфоксиді з концентраціями 5, 10 і 15 мас.\%. Висловлено припущення, що часовій еволюції діелектричної проникності відповідає зміна надмолекулярної структури полімерного розчину, яка має флуктуаційну природу і пов'язана з процесом встановлення рівноваги у розчині полімеру. За допомогою закону відповідних станів показана подібність кінетики встановлення рівноваги у системах полівініловий спирт-диметилсульфоксид і гліцерин-вода. Запропонована математична модель, яка дозволила визначити характерні часи життя та осциляції мікронеоднорідностей у досліджуваних розчинах полівінілового спирту. 